\title{
Prevention of Childhood Blindness through the Integration with Maternal Eye Care Programmes
}

\author{
RE Duke MSC (CEH) FWACS ${ }^{1}$, GE Patrick-Ferife MSc (CEH) FNMC, ${ }^{2}$ EN Ogbedo, FWACS ${ }^{3}$, F \\ Omoraka ${ }^{4}$ \\ ${ }^{1}$ Consultant/Community Ophthalmologist, University of Calabar Teaching Hospital, Calabar, Cross River State \\ ${ }^{2}$ Consultant/Community Ophthalmologist, Ministry of Health, Asaba and Project Director, EyeCARE Health Initiative, Delta State \\ ${ }^{3}$ Consultant Ophthalmologist, Okwe General Hospital, Okwe - Asaba, Delta State \\ ${ }^{4}$ Consultant Physician, Central Hospital, Sapele, Delta State
}

\section{SUMMARY}

Objective: The prevention of childhood blindness through the provision of preventive services at the community level, specialized surgical services in ophthalmic units and the provision of devices to correct low vision and services to children with established visual loss.

Materials and methods: A series of free surgical cataract eye camps which focused on only women were conducted throughout Delta State in which children with eye problems were incidentally identified and treated. Of the 4239 women seen, 1006 (24\%) brought their children along with them. Out of the 1006 children that accompanied their mothers, 840 (83\%) were seen based on the request of their mothers for their ocular examination. Of these children, 28 (3\%) had ocular morbidity. There were 19 boys and 9 girls. The majority of the children were between 2 to 5 years of age. The commonest causes of ocular morbidity were congenital and developmental cataract $(24 \%)$, vernal conjunctivitis (28\%), congenital glaucoma (14\%) and corneal opacity from measles, harmful traditional eye practises and severe vernal keratoconjunctivitis. Others were refractive error, strabismus and optic atrophy.

Results: A total of 10 children underwent surgery. Surgical procedures included 4 lensectomy and 3 lensectomy with intraocular lens implantation, 2 trabeculectomy and 1 optical iridectomy. One patient was given spectacles for juvenile onset myopia.

Conclusion: There is a potential for a female gender focused eye programme, to promote child eye health and prevent childhood blindness.

Key words: childhood blindness; community; cataract; glaucoma

\section{INTRODUCTION}

Many of the causes of childhood blindness are avoidable, being either preventable or treatable. ${ }^{1}$ only $3 \%$ of the world's blind population are children. However, because children have a lifetime of blindness ahead of them, the number of 'blind person years' resulting from blindness starting in childhood is second only to cataract. ${ }^{2}$ Controlling blindness in children is a priority of VISION 2020,,$^{3,4}$ however, as its causes differ from that of blindness in adults, different strategies, personnel, infrastructure, and equipment are required to combat it. There is also a greater urgency when managing children, as delays in treatment can lead to amblyopia. $^{5}$

Maternal health intervention programmes have existed for many years. It is assumed that such programmes, while reducing maternal mortality and improving women's health, could simultaneously, reduce childhood blindness. Such programmes include rubella vaccination in developed countries, nutrition and vitamin A programmes during pregnancy and lactation for the prevention of vitamin A deficiency and sexually transmitted disease clinics to prevent ophthalmia neonatorum. ${ }^{6}$

The integrated maternal and neonatal health (IMNH) strategy is an integrated health care initiative with a target of reaching $90 \%$ of the population of women, neonates and children in Nigeria by the year 2020. One of the interventions under the strategy is the maternal population-oriented outreach and mobile specialty clinics. ${ }^{7}$ Such an intervention is what is analyzed and documented in this report which describes the potential of using female gender eye programmes to promote child eye health and prevent childhood blindness.

\section{MATERIALS AND METHOD}

Master Care Foundation "I CARE", an indigenous non government organization which focuses on poverty 
alleviation and economic emancipation of women at the lower socioeconomic level of the society in Delta State, initiated a female targeted cataract surgical camp between July and September 2007 to facilitate achievement of its goals. Announcements specifically for women with eye problems were made through town criers, radio and TV jingles. No mention of children or childhood eye problems were mentioned in any of the announcements. The number of mothers who came with children was documented. Also documented, were the number of mothers who requested an eye examination for their children. Such children had examinations performed by the paediatric ophthalmologist who was a member of the eye care team; these examinations included a general physical examination, visual acuity assessment using candy beads (100\&1000) and a local picture chart where indicated, an anterior segment examination with a penlight, a refraction using a battery operated retinoscope and a portable lens rack and ophthalmoscopy with a direct ophthalmoscope for which the Bruckner reflex was informative. A diagnosis was made on each child reviewed. A treatment option was discussed with each mother. The options included; medical treatment, optical treatment and surgical services. All of these services were offered at the camp site which was the base hospital and a secondary eye care centre which offered cataract and refractive services mainly. All paediatric surgeries were performed under general anaesthesia provided by a consultant anesthesiologist. Surgery was performed by the paediatric ophthalmologist using a microscope and a portable visited anterior vitrectomy machine when needed. Follow-up visit appointments were given to patients to come to the base hospital, while referrals to the Paediatric Eye Unit of the University of Calabar Teaching Hospital where made.

\section{RESULTS}

The female gender cataract surgical camp project in Delta State was held between July to September of 2007. The service was offered in the three senatorial districts of the state. Of the 4239 women seen, 1006 (24\%) brought their children along with them. Out of the 1006 children that accompanied their mothers, 840 (83\%) of them were seen based on their mothers' request for their ocular examination. Of these, 28 (3\%) children had ocular morbidity: 19 boys and 9 girls. The majority of the children were between 2 and 5 years of age. The commonest causes of ocular morbidity were congenital and developmental cataract $(24 \%)$, vernal conjunctivitis (28\%), congenital glaucoma (14\%) and corneal opacity from measles, harmful traditional eye practises and severe vernal keratoconjunctivitis. Others were refractive error, strabismus and optic atrophy.
A total of 10 children had surgical procedures. These included: 4 lensectomy and 3 lensectomy with intraocular lens implantation, 2 trabeculectomy and 1 optical iridectomy. One patient was given spectacles for juvenile onset myopia.

Table 1. The number of children with ocular morbidity and their age and sex distribution

\begin{tabular}{lcccc}
\hline Age range & M & F & No & $\%$ \\
\hline $0-28$ days & 0 & 0 & 0 & 0 \\
$<1$ yr & 6 & 1 & 7 & 25 \\
$<1-5$ yrs & 9 & 4 & 13 & 61 \\
$<5-10$ yrs & 4 & 4 & 8 & 14 \\
$<10-15$ yrs & 0 & 0 & 0 & 0 \\
TOTAL & 19 & 9 & 28 & 100 \\
\hline
\end{tabular}

Table 2. Causes of childhood ocular morbidity in 28 children

\begin{tabular}{|c|c|c|c|c|}
\hline \multirow[t]{2}{*}{ Ocular morbidity } & \multirow{2}{*}{$\begin{array}{l}\text { No of } \\
\text { patients }\end{array}$} & \multirow[t]{2}{*}{$\%$} & \multicolumn{2}{|c|}{ Sex } \\
\hline & & & M & $\mathrm{F}$ \\
\hline Refractive error & 4 bilateral & 14 & 3 & 1 \\
\hline Developmental cataract & 3 bilateral & 10 & 3 & 0 \\
\hline \multirow[t]{2}{*}{ Congenital glaucoma } & 4 bilateral & 14 & 3 & 1 \\
\hline & 1 unilateral & & & \\
\hline \multicolumn{5}{|l|}{ Corneal opacity } \\
\hline \multirow{3}{*}{$\begin{array}{l}\text { - } \text { measles } \\
\text { - } \text { suspicious use of } \\
\text { HTEM }\end{array}$} & 1 bilateral & 3 & 0 & 1 \\
\hline & & & & \\
\hline & 1 bilateral & 3 & 1 & 0 \\
\hline \multicolumn{5}{|l|}{ - Severe vernal } \\
\hline keratoconjunctivitis & 1 unilateral & 3 & 1 & 0 \\
\hline Refractive error & 1 bilateral & 3 & 1 & 0 \\
\hline \multicolumn{5}{|l|}{ Vernal keratoconjunctivitis } \\
\hline & 8 bilateral & 28 & 4 & 4 \\
\hline Others & & 17 & 3 & 2 \\
\hline - $\quad$ Strabismus & 2 & & & \\
\hline • $\quad$ Retinitis & & & & \\
\hline Pigmentosa & 1 bilateral & & & \\
\hline - Cortical visual & & & & \\
\hline Impairment & 1 bilateral & & & \\
\hline - Optic atrophy & 1 unilateral & & & \\
\hline TOTAL & 28 & 100 & 19 & 9 \\
\hline
\end{tabular}

At six weeks, out of 28 children with ocular morbidity, $16(57 \%)$ children presented for a follow up visit at the secondary eye centres (base hospital). Out of the 10 children who had surgical interventions, 9 (90\%) presented to the base hospital for a follow-up appointment in the sixth week, without special reminders or invitation. Fifty per cent of children had a good visual outcome at six weeks.

The mother that had refused trabeculectomy later presented to the Paediatric Eye Clinic at Calabar for surgery. 
She however delayed presentation for surgery due to financial difficulties and long distance from home. Five other children referred for further evaluation and investigation and rehabilitation did not turn up at the paediatric eye clinic in Calabar. Neither did any child come to the paediatric eye centre for the second eye operation.

\section{DISCUSSION}

The prevalence of blindness is significantly reduced where an efficient and effective planned eye care programmes exist. $^{8}$ The prevalence of childhood blindness similarly decreases if the general heath conditions are improved and if specific eye care programmes are targeted to this population. ${ }^{9}$

The children who received eye care in this review had accompanied their mothers who were attending an cataract eye camp for women. The advantages were the convenience of timing, the assurance of professional eye care and the introduction and encouragement to take up eye care services in a particular location. In addition, a combined programme replaces competing calls for a mother or child programme. Further research in recruiting visually impaired children into eye care services through a gender focussed cataract surgical eye camp needs to be carried out to ascertain the efficiency in number and quality of visual outcomes; considering the risk of delay in presentation and subsequent amblyopia.

A challenge with this method is that the children exceed the critical/amblyogenic period of their lives thereby giving a poor prognosis for visual rehabilitation after interventions. As seen in the report , $40 \%$ of children had moderate visual impairment and required amblyopia therapy.

The key informant method for identifying blind and visually impaired children, which is a known communitybased programme, has been shown to be successful for the identification and referral of childhood cataracts to tertiary facilities in some countries in East Africa and Bangladesh.,10,11 The 'integration' method reviewed in this paper needs to be scientifically tested and compared with the key informant method for efficiency and effectiveness. Most of the children in this report who were blind were boys; when compared to other community methods, such as the key informant method, where girls predominated. This may be explained by the fact that the key informant method seeks out children for service delivery (provider based) while the female gender-based cataract eye camps only saw children brought to the facility by their mothers or caregivers(patientbased). This may be a disadvantage because not all the children that need the service would be brought to the eye care facility and traditionally in our society boys are given priority over girls. Sustainability of the female only gender camp and its potential to attract children with eye problems may be a challenge because it is a vertical programme.

Over $57 \%$ of the mothers brought their children back to the eye clinic where initial contact with an ophthalmologist was made for the six week follow-up visit. Ninety percent of those that had surgery came back after six weeks for their follow up visit. Initial and subsequent follow-up for children following surgery is essential to identify complications, and the treatment of amblyopia, consequently, the development of visual until adult hood.

In Nigeria, the integration of childhood blindness and low vision programmes into the IMNCH programme ${ }^{7}$ for early identification, treatment and referral of blinding or low vision childhood disorders is suggested.

Table 3. Grade of visual acuity outcome of 9 patients at 6 weeks post operative period

\begin{tabular}{l|c|c}
\hline Grade of visual acuity & $\begin{array}{c}\text { Number of } \\
\text { patients }\end{array}$ & $\%$ \\
\hline $6 / 6-6 / 18$ & 1 & 11 \\
$<6 / 18-6 / 36$ & 4 & 45 \\
$<6 / 36-6 / 60$ & 2 & 22 \\
$<6 / 60-3 / 60$ & 1 & 11 \\
$<3 / 60-P 1$ & 1 & 11 \\
\hline TOTAL & 9 & 100 \\
\hline
\end{tabular}

Integration of practical childhood blindness prevention into primary eye care training to address family-oriented, community-based services is necessary. This would facilitate early and prompt referrals for uptake of services of existing eye care facilities.

This method of identifying children may have negative implications for a child if the mother has no eye problem. However, it is of note that some mothers brought the children because of the call to take up services, not because they had any eye problem.

None of the children reported for second eye surgery to the paediatric eye care facility, this may be as a result of the cost of the surgery and the long distance. Developing childfriendly eye hospitals with adequate and trained human resources and technology in each state of the federation, as well as creating tertiary child eye care centres with up to date infrastructures and technology in at least twelve major centres of the geo-political regions in Nigeria to ensure early referrals are appropriately and adequately managed is suggested by the year 2020. This would address the individually-oriented clinical services. 
At six-week follow-up, mothers who also had follow-up appointments came along with their children. Ensuring a well- organized and integrated management team to coordinate the vertical sequence of services, as well as ensuring the horizontal link between mother and child, such as the convenience of combining appointment visits for both mother and child needs to be looked into.

The report illustrates that in a situation in which a structured programme of prevention of childhood blindness is absent, and likewise a referral network of eye care facilities does not exist, a method of identifying and treating children with surgical blinding conditions in communities by targeting gender sensitive programmes, such as female only cataract camps despite its limitations, can be effective.

\section{CONCLUSION}

A female gender cataract surgical eye camp is a vertical eye care service focussed on prevention of avoidable blindness in women. Such a planned project inadvertently attracted a number of children with ocular diseases. Children also benefited from the planned surgical eye care services. It is, therefore, possible to merge a female only cataract eye camp with a children's eye camp and achieve satisfactory initial turn out and follow-up visits. Maternal health programmes could be unified and occur concurrently with programmes for child eye care. This strategy merits further study and consideration.

\section{REFERENCES}

1. Gilbert C, Rahi J, Quinn G. Visual impairment and blindness in children. In: Johnson, Minassian, Weale,
West, eds. Epidemiology of Eye Disease. 2nd edition. London: Arnold Publishers, 2003.

2 Rahi JS, Gilbert CE, Foster A et. al. Measuring the burden of childhood blindness. Br J Ophthalmol 1999;83: 387-8.

3 World Health Organization. Global initiative for the elimination of avoidable blindness. WHO/PBL/97.61.Geneva: WHO, 1997.

4 World Health Organization. Preventing blindness in children. WHO/PBL/00.77. Geneva: WHO, 1997.

5 Gilbert C, Gogate P. Blindness in children: a worldwide perspective. J Comm Eye Health 2007; 20(62): 32-33.

6 Black RE et al., Maternal and child under nutrition: global and regional exposures and health consequences, The Lancet, 2008, 371(9608), p. 253.

7 www.unicef.organization.ng_publications_IM NCHbrochure.pdf

8 Faal, Hannah et al. Evaluation of a National Eye Care Programme: Re-survey after 10 Years. J Comm Eye Health 2001; 14(39): 50.

9 Muhit MA. Finding blind children: methodology. J Comm Eye Health 2007;62(20): 30-31.

10 Muhit MA, Shah S, Gilbert CE, Foster A. Causes of severe visual impairment and blindness in Bangladesh: a study of 1935 children. Br J Ophthalmology 2007; 91: 1000-4.

11 Kaula K, Patel D, Muhit M, Courtright P, Causes of blindness among children identified through the use of village key informants in Malawi. Can J Ophthalmol 2008; 43: 425-7. 